\title{
Lean rats with hypothalamic pro-opiomelanocortin overexpression exhibit greater diet-induced obesity and impaired central melanocortin responsiveness
}

\author{
G. Li $\cdot$ Y. Zhang $\cdot$ K. Y. Cheng $\cdot$ P. J. Scarpace
}

Received: 3 January 2007 / Accepted: 15 March 2007 / Published online: 16 May 2007

(C) Springer-Verlag 2007

\begin{abstract}
Aims/hypothesis Central pro-opiomelanocortin (Pomc) gene therapy ameliorates genetic- or age-related obesity. We hypothesised that this treatment would delay or prevent dietary obesity in young, lean rats.

Materials and methods Recombinant adeno-associated virus encoding Pomc (rAAV-Pomc) was delivered bilaterally into the basomedial hypothalamus of lean rats for 42 days. Food intake, body weight, serum hormones, brown adipose tissue (BAT) uncoupling protein 1 (UCP1) and mRNA levels of hypothalamic neuropeptides and melanocortin receptors were assessed. Beginning on day 43, half of the rats remained on chow while the others received a high-fat diet for 89 days. We examined energy balance and responsiveness to the melanocortin agonist melanotan II (MTII) or the antagonist SHU9119.

Results Pomc gene delivery produced elevated hypothalamic Pomc mRNA (fourfold) and $\alpha$-melanocyte-stimulating hormone levels in the arcuate nucleus (twofold). Food intake and body weight were not altered by rAAV-Pomc in rats fed standard-chow. In rAAV-Pomc rats at day 42, perirenal fat and serum leptin decreased but overall visceral adiposity did
\end{abstract}

G. Li $\cdot$ Y. Zhang $\cdot$ K. Y. Cheng $\cdot$ P. J. Scarpace $(\bowtie)$

Department of Pharmacology and Therapeutics,

University of Florida College of Medicine,

Box 100267, Gainesville, FL 32610, USA

e-mail: scarpace@ufl.edu

G. Li

Department of Medicine,

University of Florida College of Medicine,

Gainesville, FL, USA

Y. Zhang

Research Service,

Malcom Randall Veterans Affairs Medical Center,

Gainesville, FL, USA not; expression of the hypothalamic agouti-related protein (Agrp) mRNA was elevated, whereas expression of melanocortin 3 and 4 receptor mRNA was reduced; BAT UCP1 protein increased nearly fourfold. The rAAV-Pomc rats fed the high-fat diet consumed more energy and gained more body weight compared with chow- or high-fat-fed controls that did not receive Pomc gene delivery. The anorexic response to MTII was impaired, whereas the orexigenic effect of SHU9119 was enhanced by rAAV-Pomc pretreatment. Conclusions/interpretation Delivery of the Pomc gene alters energy homeostasis in lean rats, predisposing them to dietinduced obesity. Diminished hypothalamic melanocortin receptors, increased Agrp expression, and potential rewiring of brain circuits may underlie the exacerbated obesity.

Keywords Diet-induced obesity - Gene transfer . Hypothalamus · Melanocortin · Pro-opiomelanocortin

$\begin{array}{ll}\text { Abbreviations } \\ \text { ACSF } & \text { artificial cerebrospinal fluid } \\ \text { AGRP } & \text { agouti related protein } \\ \text { ARC } & \text { arcuate nucleus } \\ \text { BAT } & \text { brown adipose tissue } \\ \text { EWAT } & \text { epididymal white adipose tissue } \\ \text { HF } & \text { high-fat diet } \\ \text { MC3R } & \text { melanocortin } 3 \text { receptor } \\ \text { MC4R } & \text { melanocortin } 4 \text { receptor } \\ \alpha \text {-MSH } & \alpha \text {-melanocyte-stimulating hormone } \\ \text { MTII } & \text { melanotan II } \\ \text { NPY } & \text { neuropeptide Y } \\ \text { POMC } & \text { pro-opiomelanocortin } \\ \text { PVN } & \text { paraventricular nucleus } \\ \text { PWAT } & \text { perirenal white adipose tissue } \\ \text { rAAV } & \text { recombinant adeno-associated virus }\end{array}$


rAAV-Pomc rAAV encoding Pomc

RTWAT retroperitoneal white adipose tissue

UCP1 uncoupling protein 1

WAT white adipose tissue

\section{Introduction}

The hypothalamic melanocortin system is a key leptin target in the brain and plays a critical role in the regulation of energy balance and glucose metabolism [1-6]. Melanocortins are peptides derived from a common prehormone, pro-opiomelanocortin (POMC). Among them, $\alpha$-melanocyte-stimulating hormone $(\alpha-\mathrm{MSH})$ is a major regulator of feeding and body weight [7]. Binding of $\alpha$-MSH to the melanocortin 4 (MC4R) and/or melanocortin 3 (MC3R) receptor in the hypothalamus results in a reduction in food intake and an increase in energy expenditure. Rodents with POMC deficiency and humans with POMC mutations are hyperphagic and obese [8,9]. Disruption of MC3R or MC4R also leads to obese phenotypes in rodents $[2,5,10]$.

Animals and humans usually become overweight and obese after prolonged exposure to diets rich in fat and energy. It is widely believed that increased consumption of high-energy diets in conjunction with or without changes in energy expenditure (e.g. a sedentary lifestyle) contributes to the current global obesity epidemic. Diet-induced obesity is characterised by hyperleptinaemia, hyperinsulinaemia and blunted responsiveness to exogenous leptin, thus denoting leptin resistance [11-13]. Considerable evidence indicates that the melanocortin system is downstream of the hypothalamic leptin-signalling pathway. Leptin activates POMC neurons and suppresses agouti-related protein (AGRP) in the arcuate nucleus (ARC), resulting in a rise in Pomc expression and a reduction in Agrp mRNA [14-18]. Moreover, the upregulation of Pomc by leptin is impaired in leptin resistance associated with diet-induced obesity and adult-onset obesity $[19,20]$. Such resistance renders the use of leptin futile in treating obesity in animals and humans with diet-induced obesity. On the contrary, melanotan II (MTII) and other melanocortin analogues ameliorate obesity effectively in leptin-resistant rodents [21-25]. Furthermore, chronic hypothalamic overexpression of Pomc by delivery of the Pomc gene via recombinant adeno-associated virus (rAAV) partially reverses the obese and diabetic phenotypes in genetically obese falfa (Lepr/Lepr) rats and those with adult-onset obesity [26, 27]. However, the question remains whether similar treatment in young rats will produce resistance to dietary obesity.

In the present study, we aimed to activate the melanocortin system chronically by delivery of the Pomc gene into the hypothalamus of lean rats. Subsequently, these rats were challenged with a high-fat diet. We hypothesised that Pomc overexpression in the hypothalamus would confer protection against the normal consequences of high-fat feeding, and therefore delay or prevent the development of dietinduced obesity. The results of the present study, however, sharply contradicted our postulate.

\section{Materials and methods}

\section{Description and administration of rAAV vectors}

Recombinant AAV vectors encoding the full-length $935 \mathrm{bp}$ murine Pomc cDNA (rAAV-Pomc) [28] or an enhanced form of green fluorescent protein (rAAV-Control) under the control of the hybrid cytomegalovirus immediate early enhancer/chicken $\beta$-actin promoter were prepared as previously described [27]. Vectors $\left(2.51 \times 10^{10}\right.$ particles per injection in $1 \mu \mathrm{l}$ ) were injected into the basomedial hypothalamus using coordinates targeting the ARC [27].

\section{Experimental design and diet}

This study consisted of three phases (Fig. 1a). Initially, there were two groups of 3-month-old male F344×Brown Norway rats obtained from Harlan Sprague-Dawley (Indianapolis, IN, USA): those given rAAV-Control and those given rAAV-Pomc. rAAV-Control and rAAV-Pomc rats were allowed free access to food and water. In the first phase, rats were administered rAAV-Control or rAAV-Pomc and fed standard chow containing $15 \%$ of energy as fat; $13.9 \mathrm{~kJ} / \mathrm{g}$ (3.3 kcal/g) (diet 2018; Harlan Teklad, Madison, WI, USA) for 42 days. At this point, 12 animals from each group were removed: six for tissue analysis such as fat mass analysis, serum hormone measurement, and determination of hypothalamic neuropeptide and melanocortin receptor mRNA, and the other six for micropunches of specific hypothalamic nucleus-containing tissues to determine $\alpha$-MSH and $\beta$-endorphin levels. In the second phase, 42 days after gene delivery, each group was divided; onehalf continued on standard chow while the other half received a high-fat diet containing $60 \%$ of energy as fat; $21.9 \mathrm{~kJ} / \mathrm{g}$ (5.2 kcal/g) (D12492; Research Diets, New Brunswick, NJ, USA) for an additional 89-day period ( $n=$ 6-8 per group). In the third phase, the two high-fat-fed groups (HF-Pomc and HF-Control) were examined for their responsiveness to central MTII infusion followed by that to SHU9119. A cannula (Brain Infusion Kit II; Durect, Cupertino, CA, USA) was stereotaxically inserted into the left lateral cerebral ventricle, and was connected to a miniosmotic pump (Alzet; Durect) implanted in a dorsal subcutaneous pocket through a catheter with a length of $9.7 \mathrm{~cm}$. The length of the catheter, and hence the volume inside it $(36 \mu \mathrm{l})$, provided a 3 day lag time before the 
Fig. 1 a Experimental scheme, b hypothalamic Pomc expression and $\mathbf{c} \alpha$-MSH levels in selected hypothalamic areas. a Refer to Materials and methods for description. b Pomc mRNA levels 42 and 185 days after vector delivery. Control values were set to 100. c RIA analysis of tissue $\alpha$-MSH levels in the $\mathrm{ARC}, \mathrm{PVN}$ and lateral hypothalamic area (LH) 42 after vector delivery. rAAV-Control, white bar; rAAV-Pomc, black bar. Data are mean \pm SE from six to eight rats per group. ${ }^{*} p<0.05$, $* * p<0.01$ vs control

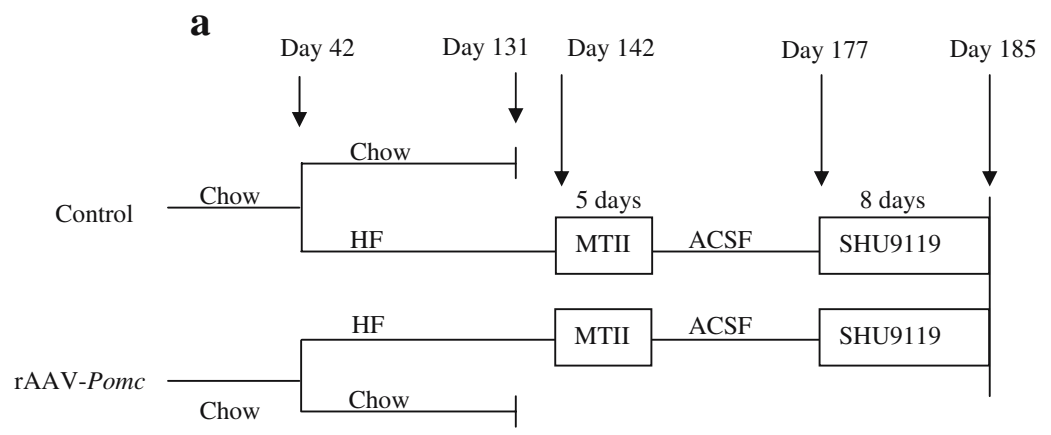

b

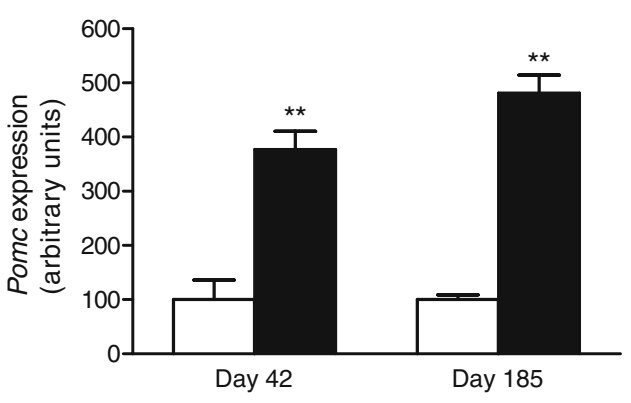

c

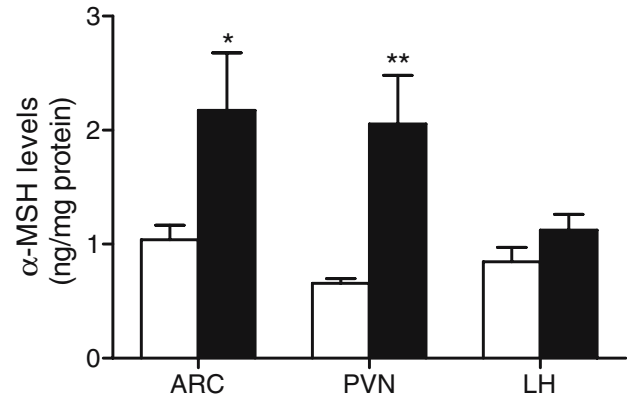

treatment solutions could be delivered via an Alzet-2002 mini-osmotic pump (delivery rate $0.5 \mu \mathrm{l} / \mathrm{h}$ ). Artificial cerebrospinal fluid (ACSF) was infused for the first 7 days after cannula implantation; the original mini-osmotic pump was replaced later by a new pump containing MTII. A small air bubble was introduced at the mini-pump end of the catheter to prevent mixing of ACSF and MTII solutions. The total infusion period was 8 days, consisting of 3 days of ACSF (due to the 3 day lag period in the catheter) and 5 days with MTII $(0.5 \mathrm{nmol} /$ day $)$. A second pump change allowed the infusion of ACSF for 4 weeks. Then a third pump change was made to provide SHU9119 (0.2 nmol/ day); the total of 11 days of infusion consisted of 3 days of ACSF and 8 days of SHU9119 infusion. All mini-osmotic pumps were primed overnight at $37^{\circ} \mathrm{C}$.

Tissue harvesting and preparation

Rats were killed by cervical dislocation under $100 \mathrm{mg} / \mathrm{kg}$ pentobarbital anaesthesia. Cardiac blood, hypothalamus, brown adipose tissue (BAT) and perirenal, retroperitoneal and epididymal white adipose tissues (PWAT, RTWAT and EWAT, respectively) were obtained as previously described [26]. To obtain micropunches of specific hypothalamic nucleus-containing tissues, two groups of rats (six rats in each of the rAAV-Pomc and rAAV-Control groups) were killed and the brains were rapidly excised, chilled on icecold saline and sliced using a Stoelting tissue slicer (Stoelting, Wood Dale, IL, USA). Brains were sectioned at 0,2 and $5.0 \mathrm{~mm}$ relative to the anterior commissure, as previously described [27]. The paraventricular nucleus
(PVN) was removed from the 0 and $2 \mathrm{~mm}$ slices, and the $\mathrm{ARC}$ and lateral hypothalamic area were removed from the 2 and $5 \mathrm{~mm}$ slices with a tissue punch. Micropunched hypothalamic tissue samples were boiled and sonicated in $0.5 \mathrm{ml}$ of $0.1 \mathrm{~mol} / 1$ acetic acid. Homogenates were centrifuged $(13,000 \mathrm{~g})$ for $15 \mathrm{~min}$. To assay for protein, $60 \mu \mathrm{l}$ of supernatant fraction was taken from each sample and the remainder stored at $-80^{\circ} \mathrm{C}$ until RIA analysis for $\alpha$ MSH and $\beta$-endorphin (Phoenix Pharmaceuticals, Belmont, CA, USA).

Serum leptin and insulin

Serum leptin and plasma insulin levels were measured using rat RIA and ELISA kits, respectively (Linco Research, St Charles, MO, USA).

\section{RT-PCR}

Expression levels of mRNAs for Pomc, neuropeptide Y (Npy), Agrp, Mc3r, Mc4r in the hypothalamus were identified by relative quantitative RT-PCR using a QuantumRNA 18S Internal Standards kit (Ambion, Austin, TX, USA) as previously described [27].

\section{Uncoupling protein 1}

Immunoreactive uncoupling protein 1 (UCP1) in BAT homogenates was determined using an antibody specific for rat UCP1 (Linco Research) as previously described [19]. 
Statistical analysis

Results are presented as mean \pm SE. Statistical significance was assessed by unpaired two-tailed Student's $t$ test, oneway ANOVA with the Newman-Keuls post hoc test or ANOVA with repeated measures. A value of $p<0.05$ was considered significant.

\section{Results}

Pomc gene delivery in lean rats on standard chow

\section{Hypothalamic Pomc expression and $\alpha-M S H$ production}

Overexpression of Pomc in the hypothalamus following central bilateral viral delivery was determined by RT-PCR. Pomc mRNA levels were elevated at day 42 by 3.8 -fold in chow-fed rats given rAAV-Pomc compared with those given rAAV-Control (Fig. 1b, left bars; $p<0.001$ ). Pomc overexpression resulted in a twofold increase in $\alpha$-MSH in the ARC and PVN, but not the lateral hypothalamic area (Fig. 1c). The $\beta$-endorphin levels were also elevated in the ARC of rAAV-Pomc rats $(3.17 \pm 0.35 \mathrm{ng} / \mathrm{mg}$ protein; $p<$ $0.05)$ compared with controls $(1.87 \pm 0.20 \mathrm{ng} / \mathrm{mg}$ protein).

\section{Food intake and body weight}

Food intake did not differ between rAAV-Pomc and rAAVControl rats fed the standard chow diet throughout the 131 day experimental period (Fig. 2a). Before and on the day of vector delivery, the body weights of the two groups were comparable ( $265 \pm 9$ vs $264 \pm 9 \mathrm{~g}$ at day 0 ), and remained nearly identical following Pomc gene delivery (Fig. 2b).

\section{Visceral adiposity and serum leptin and insulin levels}

At day 42, six rats from each group were removed from the study for tissue analysis. Despite the lack of overt effects of Pomc in these lean rats on body weight (rAAV-Control, $332 \pm 8$; rAAV-Pomc, $335 \pm 9 \mathrm{~g}$ at day $42 ; p=0.9$ ), adiposity and non-fasting leptin levels were assessed for evidence of lipopenia. The Pomc gene delivery generated a significant reduction in PWAT $(37 \% ; p=0.014)$ but non-significant reductions in other fat depots, such as RTWAT $(11 \%, p=$ $0.53)$ and EWAT $(9 \%, p=0.42)$, compared with control rats (Table 1). When the sum of the three adipose tissues was considered, there was a non-significant decline of $10 \%$ compared with the controls. Serum leptin, another indicator of body fat mass [11], was reduced by $29 \%$ in the rAAVPomc rats relative to rAAV-Control, without reaching statistical significance $(p=0.08)$ (Table 1). Pomc gene delivery had no effect on serum insulin or corticosterone concentrations (Table 1).

\section{$B A T$}

Induction of UCP1 in BAT is an important marker of enhanced thermogenesis and thus energy expenditure in rodents [29]. The UCP1 protein levels were examined 42 days after Pomc gene delivery. There was small but significant decline in total BAT weight $(p<0.05)$ but not protein content. However, total UCP1 protein levels per BAT depot and BAT UCP1 density were elevated by $245 \%$ $(p<0.05)$ and $386 \%(p<0.01)$ respectively with the rAAVPomc treatment (Table 1).

\section{Hypothalamic Npy, Agrp, Mc3r and Mc4r mRNA levels}

We assessed the expression of mRNAs for the hypothalamic neuropeptides Npy and Agrp 42 days after Pomc vector delivery using RT-PCR (Table 1). The mRNA levels of Agrp, the endogenous antagonist of melanocortin receptors, increased by $32 \%(p<0.05)$, whereas the mRNA levels of the orexigenic neuropeptide $N p y$ remained unchanged relative to control rats.
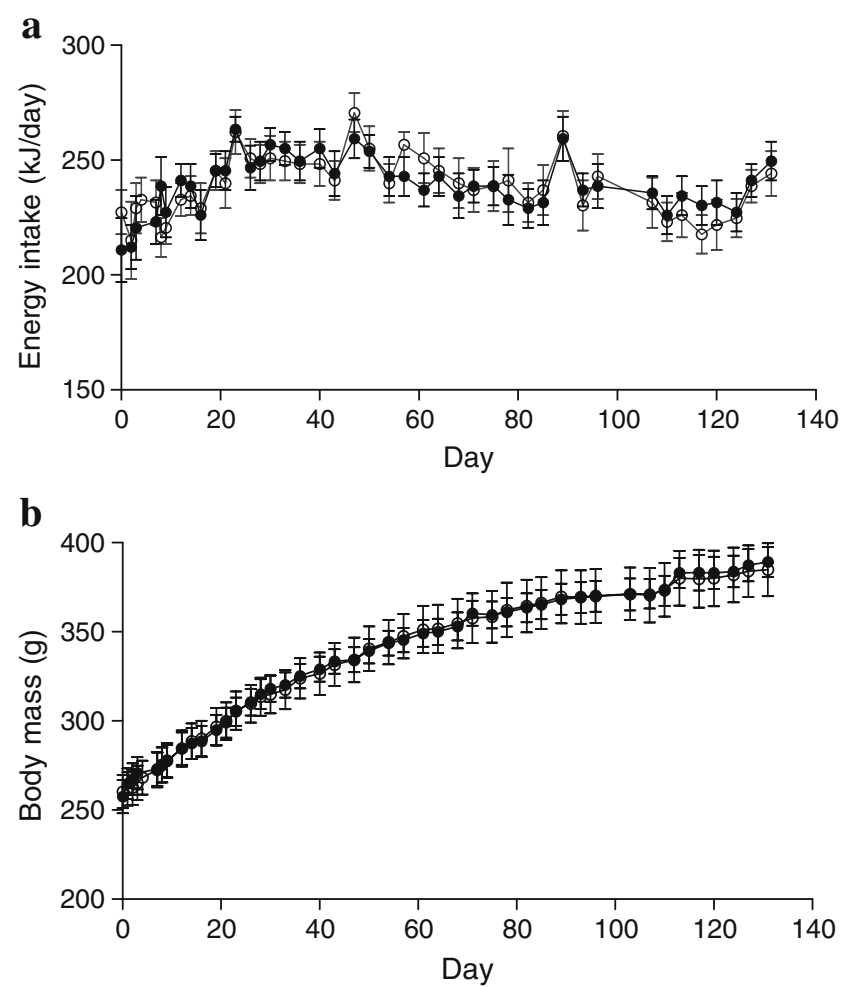

Fig. 2 a Energy intake and $\mathbf{b}$ body mass in lean rats that received either rAAV-Control (open circle) or rAAV-Pomc (closed circle) vector delivery and were fed chow diet for 131 days. Data are mean \pm SE of six rats per group 
Table 1 Tissue parameters and serum hormones 42 days after rAAVPomc or rAAV-Control delivery

\begin{tabular}{llc}
\hline & Treatment & \\
\cline { 2 - 3 } & rAAV- & rAAV- \\
& Control & Pomc \\
\hline Perirenal WAT (g) & $1.06 \pm 0.11$ & $0.67 \pm 0.07^{\mathrm{a}}$ \\
Retroperitoneal WAT (g) & $3.18 \pm 0.44$ & $2.84 \pm 0.31$ \\
Epididymal WAT (g) & $4.29 \pm 0.34$ & $3.91 \pm 0.31$ \\
Serum leptin (ng/ml) & $4.21 \pm 0.06$ & $2.91 \pm 0.32$ \\
Serum insulin (pmol/l) & $758 \pm 227$ & $659 \pm 134$ \\
Serum corticosterone (ng/ml) & $239 \pm 64$ & $313 \pm 65$ \\
BAT weight (mg) & $395 \pm 21$ & $315 \pm 26^{\mathrm{a}}$ \\
BAT protein (mg/total BAT) & $39.5 \pm 3.5$ & $31.7 \pm 4.7$ \\
UCP1 protein (arbitrary & $100 \pm 16.9$ & $386 \pm 86.9^{\mathrm{a}}$ \\
$\quad$ units/mg BAT protein) & & \\
UCP1 protein (arbitrary & $100 \pm 15.6$ & $244.8 \pm 25.3^{\mathrm{b}}$ \\
$\quad$ units/total BAT) & & \\
Npy mRNA (arbitrary units) & $100 \pm 6.5$ & $87.6 \pm 6.3$ \\
Agrp mRNA (arbitrary units) & $100 \pm 9.6$ & $132 \pm 10.6^{\mathrm{a}}$ \\
Mc3r mRNA (arbitrary units) & $100 \pm 3.9$ & $76.7 \pm 8.5^{\mathrm{a}}$ \\
Mc4r mRNA (arbitrary units) & $100 \pm 8.8$ & $67.1 \pm 8.4^{\mathrm{a}}$ \\
\hline
\end{tabular}

Data are mean $\pm \mathrm{SE}$ of six rats per group

Control tissue protein and mRNA levels were set to 100

${ }^{\mathrm{a}} p<0.05 ;{ }^{\mathrm{b}} p<0.01$ vs control (unpaired $t$ test)

Gene delivery of rAAV-Pomc for 42 days reduced the expression levels of hypothalamic $M c 3 r$ and $M c 4 r$ by $23 \%$ $(p<0.05)$ and $33 \%(p<0.05)$ respectively compared with rAAV-Control (Table 1).

\section{High-fat feeding}

\section{Food intake and body weight}

A high-fat challenge was employed to investigate whether Pomc gene delivery can prevent or delay diet-induced obesity. Forty-two days after treatment with rAAV-Pomc or rAAV-Control, some rats were provided a $60 \%$ (by energy) high-fat diet and compared with rats treated with control or Pomc vector but maintained on chow. Both the control and rAAV-Pomc rats responded to the high-fat diet with a similar degree of modest hyperphagia, which attenuated gradually during the first week. Both groups of high-fat-fed rats, however, maintained a slightly elevated level of energy consumption relative to chow-fed controls (Fig. 3a) over the entire 89-day period. Both the chow rAAV-Control and the chow rAAV-Pomc rats consumed the same amount of energy and had similar body weights during this period (Fig. 2, day 42 onward). Cumulative energy consumption during this 89 -day period was $11 \%$ greater in the high-fat fed control rats compared with either the chow rAAVControl or chow rAAV-Pomc rats (Fig. 3b). Unexpectedly, a

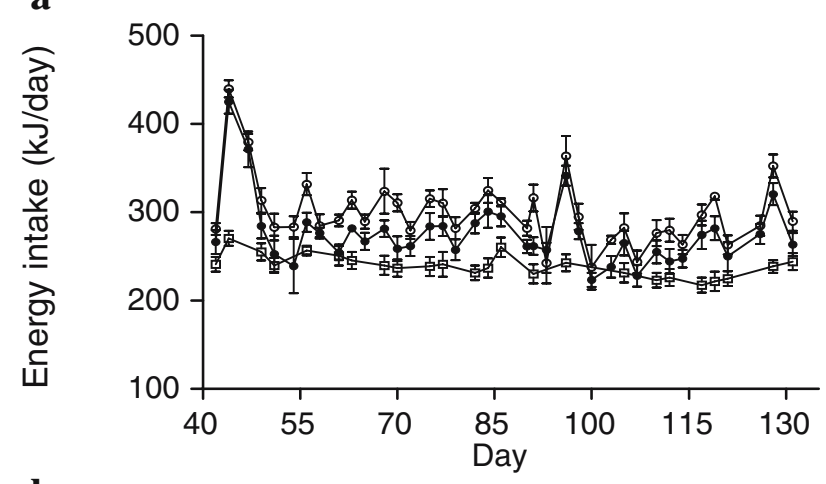

b

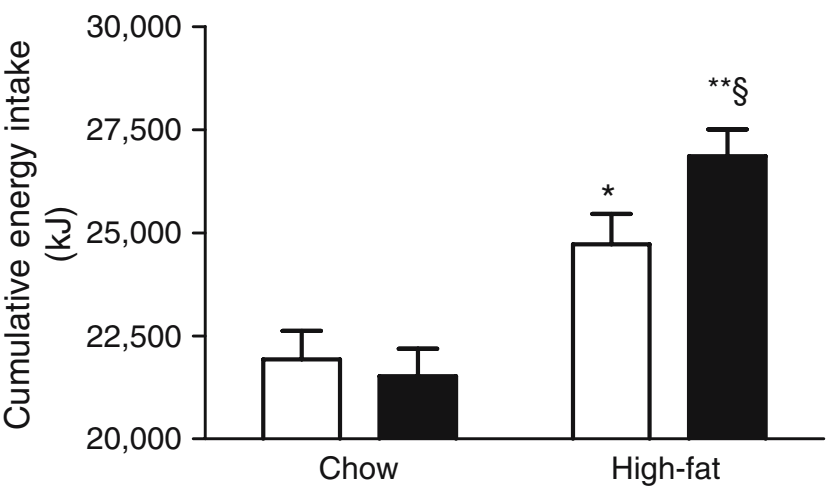

c

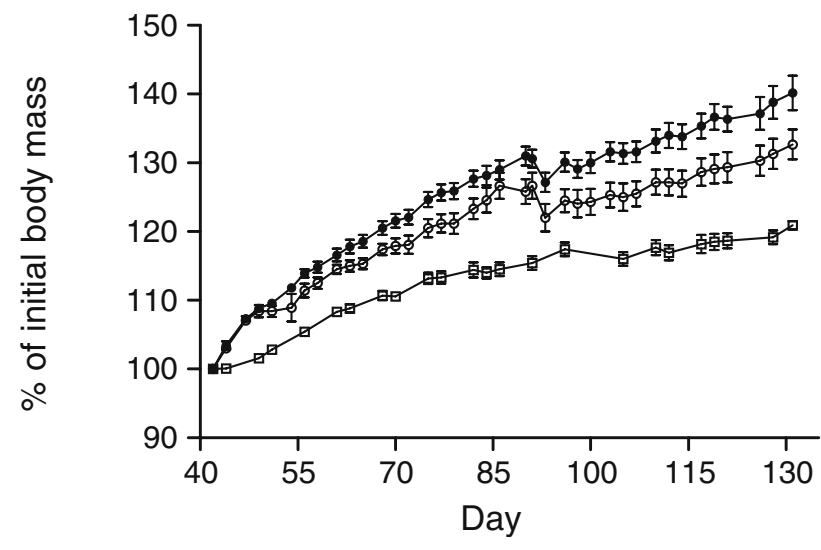

Fig. 3 a Daily energy intake, $\mathbf{b}$ cumulative energy intake and $\mathbf{c}$ body mass in rats that received either rAAV-Pomc (HF-rAAV-Pomc) or rAAV-Control (HF-rAAV-Control) for 42 days and were then fed a high-fat diet for 89 days, compared with chow-fed rAAV-Control rats. A comparison between Chow-rAAV-control and chow-fed rAAVPomc rats is shown in Fig. 2 (days 42-131). a, c, chow-rAAV-Control, open squares; HF-rAAV-Control, open circles; HF-rAAV-Pomc, closed circles. b, rAAV-Control, white bars; rAAV-Pomc, black bars. In $\mathbf{c}$ data are expressed as percentage of initial body weight at onset of high-fat feeding. ${ }^{*} p<0.05$ and ${ }^{* *} p<0.01$ vs chow-fed rAAV-Control or chow-fed rAAV-Pomc rats; ${ }^{\S} p<0.05$ vs high-fat-fed rAAV-Control (six to eight rats per group); $p<0.001$ for difference in body weight between all pairs (treatment $\times$ repeated measures ANOVA) 
the rAAV-Pomc rats fed the high-fat diet consumed $9 \%$ more energy relative to the high-fat-fed rAAV-Control rats (Fig. 3b). Whereas the high-fat-fed controls gained 55\% more body weight than either the chow rAAV-Control (Fig. 3c) or chow rAAV-Pomc rats (Fig. 2b, day 42 onwards), the rAAV-Pomc high-fat-fed rats grew even heavier $(135.4 \pm 8.5$ vs $109.6 \pm 9.1 \mathrm{~g}, p<0.05)$ relative to the high-fat-fed rAAV-Control rats.

MTII and SHU9119 infusion

\section{Effects of MTII on food intake and body weight}

To examine the possibility of melanocortin receptor desensitisation as a result of Pomc overexpression, the responsiveness to central melanocortin activation was determined by the infusion of the melanocortin agonist MTII $(0.5 \mathrm{nmol} / \mathrm{day})$ into the lateral cerebral ventricle for 5 days. This phase of the experiment only involved rats given a high-fat diet and treated with either rAAV-Pomc or rAAV-Control vectors (see Fig. 1a for experimental design). The high-fat feeding continued during this phase of the experiment. MTII induced a marked reduction $(66 \%)$ in energy intake in control rats on day 1 relative to their own baseline energy intake on day 0 (Fig. 4a). In rAAV-Pomc treated rats, the anorexic response to MTII was blunted, amounting to only a $28 \%$ decrease in food consumption on day 1 relative to food intake before MTII treatment (Fig. 4a). The anorexic effect of MTII attenuated rapidly in both groups. However, a significant rebound increase in feeding was observed in rAAV-Pomc rats on day 3 compared with controls (Fig. 4a).

The blunted responses to MTII were more apparent when changes in body weight were examined. Prior to the MTII infusion, the body weights were $454 \pm 13 \mathrm{~g}$ for rAAVPomc rats and $428 \pm 19 \mathrm{~g}$ for controls. The rAAV-Pomc animals weighed 5.0, 5.7 and $6.2 \%$ less at days 3, 4 and 5 of MTII infusion, respectively, compared with their preinfusion weight, whereas in control rats the average body weight was reduced by $7.3,8.1$ and $8.2 \%$ at the respective time points (Fig. 4b). At the end of MTII infusion, rAAV-Pomc rats lost significantly less weight compared with control rats (rAAV-Pomc, 28.0 \pm 3.7 ; rAAVControl, $40.1 \pm 2.5 \mathrm{~g} ; p=0.04)$. Meanwhile, the serum leptin level was $47 \%$ higher in the high-fat-fed rAAV-Pomc rats compared with the high-fat-fed control rats (Fig. 4c).

\section{Effect of SHU9119 on food intake and body weight}

Subsequent to the MTII infusion, all rats were infused for 4 weeks with ACSF and continued on the high-fat diet. During this period the food intakes of both groups returned to their respective baseline levels. Serum leptin levels also
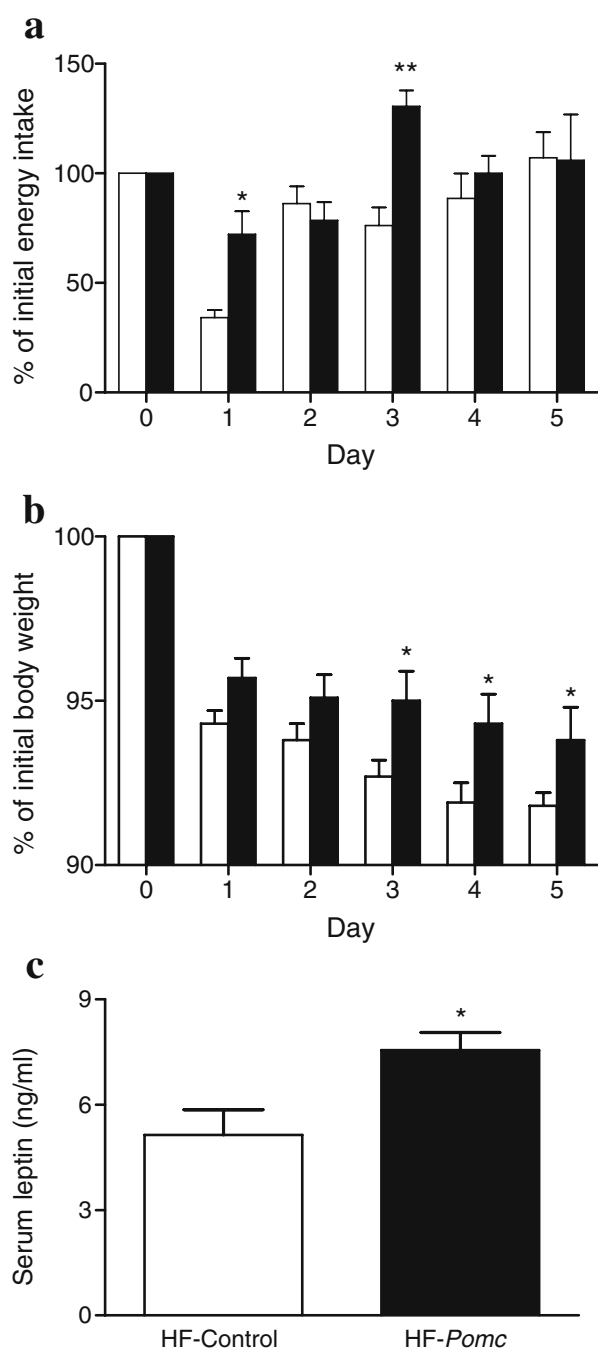

Fig. 4 a Daily energy intake and $\mathbf{b}$ body weight after 5 days of central MTII infusion in high-fat-fed rats that received rAAV-Control (HFControl) or rAAV-Pomc (HF-Pomc), and c serum leptin level at the end of the MTII infusion. Initial energy intake or body weight is defined as the 3 day average value before MTII infusion. rAAVControl, white bars; rAAV-Pomc, black bars. * $p<0.05$; ** $p<0.01$ vs HF-Control (six to eight rats per group)

converged between the two groups (determined in tail blood collected during pump changes) (Fig. 5c, left bars). At this time, SHU9119 (0.2 nmol/day) was infused for an 8 day period while high-fat feeding was continued. Although both groups of rats consumed a significantly greater amount of energy after the SHU9119 infusion, the orexigenic effect of this melanocortin antagonist was higher in rAAV-Pomc rats relative to controls, especially in the early phase of the infusion ( $p<0.05$ at days $2,3,4$ and 5 vs controls; Fig. 5a). During the later phase of SHU9119 infusion, although the hyperphagia persisted in both groups, but there were no longer statistical differences in daily food 
a

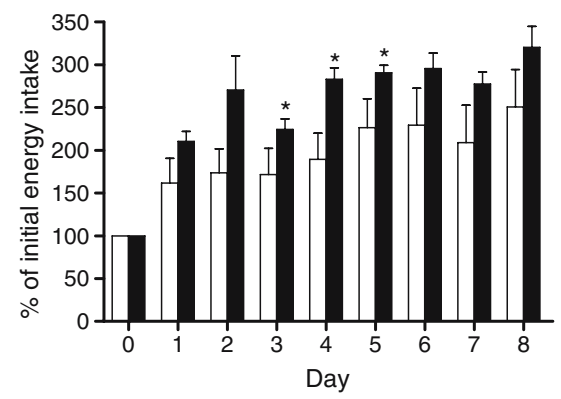

b

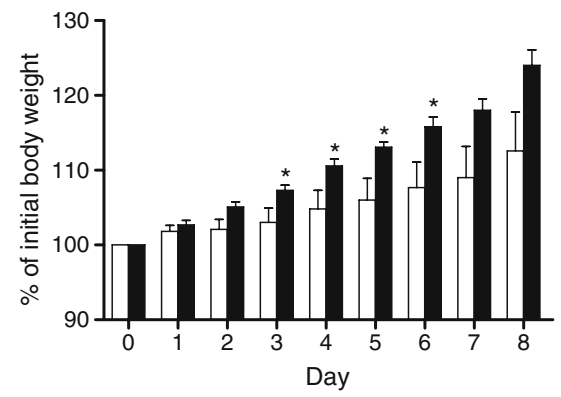

d

c
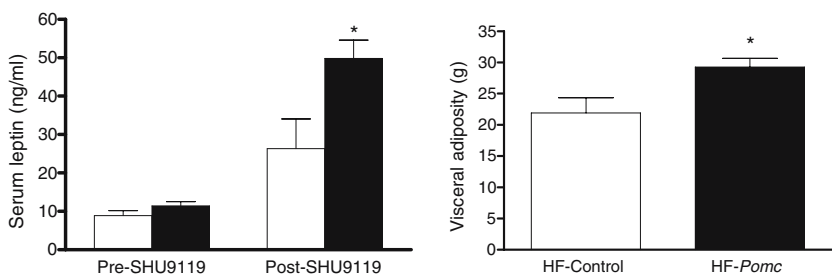

Fig. 5 a Daily energy intake and $\mathbf{b}$ body weight after 8 days of central infusion of SHU9119 in high-fat-fed rats that received rAAV-Control (HF-Control, white bars) or rAAV-Pomc (HF-Pomc, black bars). c Serum leptin and d visceral adiposity levels at the end of SHU9119 infusion. Initial energy intake or body weight is defined as the 3 day average value before SHU9119 infusion. Visceral adiposity levels are represented by the sum of perirenal and retroperitoneal WAT values. $* p<0.05$ vs HF-Control (six to eight rats per group)

intake. The cumulative energy intake during the 8 day period, however, was significantly increased in rAAV-Pomc relative to control rats (rAAV-Pomc, 5,576 \pm 235 ; rAAVControl, 3,715 $\pm 676 \mathrm{~kJ} ; p=0.03$ ).

In addition to the marked hyperphagia, 8 days of SHU9119 infusion also increased body weight significantly in the high-fat-fed rAAV-Pomc and rAAV-Control rats (Fig. 5b). Compared with their respective pre-SHU9119 baseline levels, the Pomc rats had an overall $24 \%$ weight gain compared with $12.6 \%$ in control animals (rAAV-Pomc, $113.8 \pm 8.2$; rAAV-Control, $56.1 \pm 22.4 \mathrm{~g} ; p=0.04$ ).

At the end of SHU9119 infusion, serum leptin levels were significantly elevated by $89 \%$ in the Pomc rats compared with controls (Fig. 5c), consistent with the 34\% increase in visceral adiposity, represented by the sum of perirenal and retroperitoneal white adipose tissues (Fig. 5d).
Pomc expression in the hypothalamus at day 185

Hypothalamic Pomc gene expression was evaluated again in the rats fed the high-fat diet at the end of SHU9119 infusion. One-hundred and eighty-five days after vector administration, hypothalamic Pomc mRNA levels remained elevated by fourfold in high-fat-fed rats given rAAV-Pomc compared with those given rAAV-Control (Fig. 1b, right bars).

\section{BAT UCP1 at day 185}

In contrast to the substantial increase in BAT UCP1 levels observed at day 42 prior to the infusion of MTII or SHU9119 (Table 1), at the termination of the experiment after both MTII and SHU9119 infusions, the UCP1 levels were similar in the high-fat-fed rAAV-Pomc rats and control animals (data not shown).

\section{Discussion}

Activation of the central melanocortin system by MTII and other melanocortin analogues is efficacious in reducing body weight, food consumption and adiposity in animals with diet-induced obesity [21, 22, 24, 25]. Similarly, we demonstrated that central Pomc gene delivery alleviates obesity and insulin intolerance in rats with genetic or adultonset obesity [26, 27]. These earlier experiments suggested a parallel role for melanocortin tone in the pathogenesis of age-induced obesity and diet-induced obesity and hence led to our postulate that chronic central rAAV-Pomc gene therapy in lean rats will curb the development of dietinduced obesity induced by the high-fat diet. The results from the present study are unexpected but intriguing.

First, Pomc gene delivery targeted to the ARC did not reduce food intake or body weight in the lean animals consuming a standard chow diet. The absence of an anorectic effect was not due to silencing of Pomc gene expression because hypothalamic Pomc expression was elevated when assessed either at day 42 or at the termination of the experiment, day 185. Immunohistological examination of the green fluorescent protein (GFP) staining pattern in brain slices from control animals revealed that the highest density of GFP-positive cells was in the ARC, with modest GFP staining in the ventromedial and dorsomedial hypothalamic nucleus, and that the vast majority of GFP-expressing cells had a neuronal origin (data not shown). The corresponding increases in the levels of $\alpha$-MSH in both the ARC and PVN regions of the hypothalamus were demonstrated by RIA analysis. These augmented $\alpha$-MSH levels should promote anorexic tone and probably triggered compensatory responses. Emerging evidence suggests that, in lean animals, energy intake is controlled by a nearly fully 
activated anorexic system and a mostly quiescent orexigenic system [30]. Considering this notion, the orexigenic pathway(s) are programmed to prevent anorexia in lean animals and should readily overcome a mild anorectic stimulus such as that exerted by rAAV-Pomc treatment. Our findings are consistent with two previous reports in which transgenic overproduction of POMC-derived peptides in mice did not alter food intake in lean mice [31, 32]. Despite the lack of anorexia in the present study, there is evidence that POMC affects the overall central melanocortin system. Specifically, hypothalamic $M c 3 r$ and $M c 4 r$ expressions were reduced, whereas the expression of the orexigenic neuropeptide, AGRP, was increased, as measured 42 days after rAAV-Pomc administration. These changes suggest agonist-mediated receptor desensitisation [33] accompanied by a compensatory rise in the natural melanocortin antagonist, AGRP. These two factors probably contributed to the lack of an anorexic response but provide only a simplistic explanation for it. For example, in addition to an elevation in $\alpha$-MSH levels, $\beta$-endorphin levels were also elevated in the hypothalamus. The function of this peptide in energy homeostasis is controversial, the evidence suggesting either an anorexic or an orexigenic role [34, 35]. This peptide may have an unknown role in the desensitisation observed in the present study.

The melanocortins are known to increase sympathetic outflow to BAT [24, 26, 36-38], and we observed a substantial increase in UCP1 in BAT after rAAV-Pomc treatment at day 42. Additionally, the Pomc rats had a significant reduction in PWAT as well as a trend towards a decrease in visceral adiposity (PWAT+RTWAT+EWAT) that correlated with reduced serum leptin. Collectively, these data seem to indicate an increase in energy expenditure following chronic Pomc overexpression in lean rats. However, the lack of a reduction in body weight despite a presumed increase in energy expenditure remains puzzling. Without a compensatory rise in energy consumption to balance this increase, body weight would be expected to decline. The absence of a decrease in body weight indicates that the presumed elevation in energy expenditure was so modest that it was insufficient to affect body weight significantly for the duration of the present study.

Second, the functional consequences of hypothalamic Pomc overexpression become evident following a high-fat diet challenge. When the rAAV-Pomc-pretreated rats were switched from chow to a high-fat diet, instead of resisting or delaying the onset of diet-induced obesity as we predicted, they developed greater obesity than the highfat-fed rAAV-Control rats. Since the Pomc-treated animals had moderately lower serum leptin levels and adiposity before the high-fat challenge, the brain may have perceived these lower values as a signal for negative energy balance and consequently shifted towards energy-storing mecha- nisms. The nature of this presumed shift remains unknown. We have observed similar results when leptin is centrally overexpressed in lean rats. When such rats are provided a high-fat diet, they display exacerbated weight and adiposity gain compared with high-fat-fed control rats [39]. Moreover, we have demonstrated that blockade of the leptin receptor aggravates the dietary weight gain [40]. Therefore, disruption of the normal energy homeostatic regulation in young rodents increases susceptibility to diet-induced obesity.

We also examined the responses of the high-fat-fed control and Pomc rats to the melanocortin agonist MTII and antagonist SHU9119. Central infusion of MTII evoked a transient suppression in food intake and a sustained weight reduction in rAAV-Control rats, whereas these moderate effects were attenuated in rAAV-Pomc rats. It is likely that increased $\alpha$-MSH downregulated $M c 3 r$ and $M c 4 r$ expressions as well as inducing Agrp expression in the ARC. However, because rAAV-mediated Pomc gene delivery resulted in the transfection of neural cells outside the arcuate nucleus and elevated $\alpha-\mathrm{MSH}$ as well as $\beta$ endorphin levels in both the ARC and PVN, the ectopic action of these POMC-derived bioactive peptides might account for some of the responses observed.

The exaggerated orexigenic response to the melanocortin antagonist SHU9119 in rAAV-Pomc-treated rats lends further evidence for disrupted homeostatic regulation of energy balance by the central melanocortin system. Chronic Pomc overexpression reduces $M c 3 r$ and $M c 4 r$ expressions in the hypothalamus. These changes would predict diminished SHU9119 responses with the POMC treatment. On the other hand, the increased $\alpha$-MSH production following Pomc overexpression generates elevated melanocortin tone. Heightened melanocortin tone would potentially provide more melanocortin receptor activity subject to blockade by SHU9119. In such a case, an enhanced SHU9119 response in the Pomc-treated animals compared with the control animals is expected. The increased melanocortin tone also invites opposing orexigenic responses involving perhaps both melanocortin-dependent and melanocortin-independent pathways. We favour the interpretation that SHU9119 blocks the elevated melanocortin tone, allowing heightened orexigenic pathways free reign and resulting in an exaggerated SHU9119 response. Another possible explanation involves the theory of neural rewiring of the central melanocortin system. Evidence indicates substantial plasticity between hypothalamic neuronal circuits, and such synaptic plasticity is believed to be of considerable importance in the long-term regulation of energy homeostasis [41]. NPY/AGRP neurons in the ARC not only inhibit anorexic melanocortin cells at their target site within the PVN, but also directly antagonise arcuate POMC neurons [42, 43]. Any increase in the inhibitory synaptic innervations of POMC cells by NPY/ 
AGRP terminals would enhance the response of a melanocortin antagonist. Further studies are warranted to address the dynamic interaction between the NPY/AGRP and POMC neurons following Pomc gene therapy.

Although there is no direct evidence for this, the prolonged high-fat feeding is unlikely to have been the cause of the altered MTII and SHU9119 responses in the Pomc-treated animals because diet-induced obese rats usually exhibit normal or even enhanced MTII responses [21, 24] and SHU9119 responses are normal, at least in aged obese rats [23]. Chronic central Pomc overexpression, however, resulting in elevated levels of both $\alpha$-MSH and $\beta$-endorphin, distorts the normal melanocortin tone and probably serves as the primary cause of changes in MTII and SHU9119 responses.

In conclusion, targeted Pomc gene delivery to the hypothalamus of lean rats induced a nearly fourfold increase in hypothalamic Pomc mRNA and a twofold elevation in $\alpha$ MSH level in the ARC. This treatment produced a mild reduction in visceral adiposity, an increase in hypothalamic Agrp expression, reductions in hypothalamic $M c 3 r$ and $M c 4 r$ expressions, and a marked augmentation of BAT UCP1 protein without significant change in either food intake or body weight. Despite sustained elevation of hypothalamic Pomc expression, the Pomc-treated rats on a high-fat diet were more susceptible to diet-induced obesity, characterised by increased energy consumption and weight gain, and attenuated physiological responses to MTII and exaggerated responses to SHU9119, relative to high-fat-fed control animals. In contrast to its effectiveness in ameliorating obesity syndromes associated with genetic defects or adultonset obesity, Pomc overexpression predisposes lean rats with normal genetic background to diet-induced obesity. The diminished hypothalamic $M c 3 r$ and $M c 4 r$, increased Agrp expressions and potential rewiring of brain circuits may be the underlying mechanisms. These new findings underscore our limited knowledge of the role of POMC in normal weight regulation and suggest that disturbances in melanocortin tone disrupt normal energy homeostatic mechanisms.

Acknowledgements This work was supported by the Medical Research Service of the Department of Veterans Affairs and NIH grants AG20985 and AG 026159.

Duality of interest This study involves no duality of interest.

\section{References}

1. Fan W, Boston BA, Kesterson RA, Hruby VJ, Cone RD (1997) Role of melanocortinergic neurons in feeding and the agouti obesity syndrome. Nature 385:165-168

2. Huszar D, Lynch CA, Fairchild-Huntress V et al (1997) Targeted disruption of the melanocortin-4 receptor results in obesity in mice. Cell 88:131-141
3. Mizuno TM, Mobbs CV (1999) Hypothalamic agouti-related protein messenger ribonucleic acid is inhibited by leptin and stimulated by fasting. Endocrinology 140:814-817

4. Cone RD (1999) The central melanocortin system and energy homeostasis. Trends Endocrinol Metab 10:211-216

5. Butler AA, Kesterson RA, Khong K et al (2000) A unique metabolic syndrome causes obesity in the melanocortin-3 receptor-deficient mouse. Endocrinology 141:3518-3521

6. Obici S, Feng Z, Tan J, Liu L, Karkanias G, Rossetti L (2001) Central melanocortin receptors regulate insulin action. J Clin Invest 108:1079-1085

7. Cone RD (2005) Anatomy and regulation of the central melanocortin system. Nat Neurosci 8:571-578

8. Yaswen L, Diehl N, Brennan MB, Hochgeschwender U (1999) Obesity in the mouse model of pro-opiomelanocortin deficiency responds to peripheral melanocortin. Nat Med 5:1066-1070

9. Krude H, Biebermann H, Luck W, Horn R, Brabant G, Gruters A (1998) Severe early-onset obesity, adrenal insufficiency and red hair pigmentation caused by POMC mutations in humans. Nat Genet 19:155-157

10. Chen AS, Marsh DJ, Trumbauer ME et al (2000) Inactivation of the mouse melanocortin-3 receptor results in increased fat mass and reduced lean body mass. Nat Genet 26:97-102

11. Frederich RC, Hamann A, Anderson S, Lollmann B, Lowell BB, Flier JS (1995) Leptin levels reflect body lipid content in mice: evidence for diet-induced resistance to leptin action. Nat Med $1: 1311-1314$

12. El Haschimi K, Pierroz DD, Hileman SM, Bjorbaek C, Flier JS (2000) Two defects contribute to hypothalamic leptin resistance in mice with diet-induced obesity. J Clin Invest 105:1827-1832

13. Burguera B, Couce ME, Curran GL et al (2000) Obesity is associated with a decreased leptin transport across the blood-brain barrier in rats. Diabetes 49:1219-1223

14. Schwartz MW, Seeley RJ, Campfield LA, Burn P, Baskin DG (1996) Identification of targets of leptin action in rat hypothalamus. J Clin Invest 98:1101-1106

15. Schwartz MW, Seeley RJ, Woods SC et al (1997) Leptin increases hypothalamic pro-opiomelanocortin mRNA expression in the rostral arcuate nucleus. Diabetes 46:2119-2123

16. Cheung CC, Clifton DK, Steiner RA (1997) Proopiomelanocortin neurons are direct targets for leptin in the hypothalamus. Endocrinology 138:4489-4492

17. Baskin DG, Hahn TM, Schwartz MW (1999) Leptin sensitive neurons in the hypothalamus. Horm Metab Res 31:345-350c

18. Elias CF, Kelly JF, Lee CE et al (2000) Chemical characterization of leptin-activated neurons in the rat brain. J Comp Neurol 423:261-281

19. Scarpace PJ, Matheny M, Zhang Y et al (2002) Central leptin gene delivery evokes persistent leptin signal transduction in young and aged-obese rats but physiological responses become attenuated over time in aged-obese rats. Neuropharmacology 42:548-561

20. Wilsey J, Zolotukhin S, Prima V, Scarpace PJ (2003) Central leptin gene therapy fails to overcome leptin resistance associated with diet-induced obesity. Am J Physiol Regul Integr Comp Physiol 285:R1011-R1020

21. Hansen MJ, Ball MJ, Morris MJ (2001) Enhanced inhibitory feeding response to alpha-melanocyte stimulating hormone in the diet-induced obese rat. Brain Res 892:130-137

22. Pierroz DD, Ziotopoulou M, Ungsunan L, Moschos S, Flier JS, Mantzoros CS (2002) Effects of acute and chronic administration of the melanocortin agonist MTII in mice with diet-induced obesity. Diabetes 51:1337-1345

23. Zhang Y, Matheny M, Tumer N, Scarpace PJ (2004) Aged-obese rats exhibit robust responses to a melanocortin agonist and antagonist despite leptin resistance. Neurobiol Aging 25:1349 1360 
24. Li G, Zhang Y, Wilsey JT, Scarpace PJ (2004) Unabated anorexic and enhanced thermogenic responses to melanotan II in dietinduced obese rats despite reduced melanocortin 3 and 4 receptor expression. J Endocrinol 182:123-132

25. Bluher S, Ziotopoulou M, Bullen JW Jr et al (2004) Responsiveness to peripherally administered melanocortins in lean and obese mice. Diabetes 53:82-90

26. Li G, Mobbs CV, Scarpace PJ (2003) Central pro-opiomelanocortin gene delivery results in hypophagia, reduced visceral adiposity, and improved insulin sensitivity in genetically obese Zucker rats. Diabetes 52:1951-1957

27. Li G, Zhang Y, Wilsey JT, Scarpace PJ (2005) Hypothalamic proopiomelanocortin gene delivery ameliorates obesity and glucose intolerance in aged rats. Diabetologia 48:2376-2385

28. Uhler M, Herbert E (1983) Complete amino acid sequence of mouse pro-opiomelanocortin derived from the nucleotide sequence of pro-opiomelanocortin cDNA. J Biol Chem 258:257-261

29. Cannon B, Nedergaard J (2004) Brown adipose tissue: function and physiological significance. Physiol Rev 84:277-359

30. Schwartz MW, Woods SC, Seeley RJ, Barsh GS, Baskin DG, Leibel RL (2003) Is the energy homeostasis system inherently biased toward weight gain? Diabetes 52:232-238

31. Mizuno TM, Kelley KA, Pasinetti GM, Roberts JL, Mobbs CV (2003) Transgenic neuronal expression of proopiomelanocortin attenuates hyperphagic response to fasting and reverses metabolic impairments in leptin-deficient obese mice. Diabetes 52:2675-2683

32. Savontaus E, Breen TL, Kim A, Yang LM, Chua SC Jr, Wardlaw SL (2004) Metabolic effects of transgenic melanocyte-stimulating hormone overexpression in lean and obese mice. Endocrinology 145:3881-3891

33. Shinyama H, Masuzaki H, Fang H, Flier JS (2003) Regulation of melanocortin-4 receptor signaling: agonist-mediated desensitization and internalization. Endocrinology 144:1301-1314

34. de Pedro N, Delgado MJ, Alonso-Bedate M (1995) Central administration of beta-endorphin increases food intake in goldfish: pretreatment with the opioid antagonist naloxone. Regul Pept 55:189-195

35. Low MJ, Hayward MD, Appleyard SM, Rubinstein M (2003) State-dependent modulation of feeding behavior by proopiomelanocortin-derived beta-endorphin. Ann N Y Acad Sci 994:192-201

36. Haynes WG, Morgan DA, Djalali A, Sivitz WI, Mark AL (1999) Interactions between the melanocortin system and leptin in control of sympathetic nerve traffic. Hypertension 33:542-547

37. Cettour-Rose P, Rohner-Jeanrenaud F (2002) The leptin-like effects of 3-d peripheral administration of a melanocortin agonist are more marked in genetically obese Zucker (fa/fa) than in lean rats. Endocrinology 143:2277-2283

38. Williams DL, Bowers RR, Bartness TJ, Kaplan JM, Grill HJ (2003) Brainstem melanocortin 3/4 receptor stimulation increases uncoupling protein gene expression in brown fat. Endocrinology 144:4692-4697

39. Scarpace PJ, Matheny M, Tumer N, Cheng KY, Zhang Y (2005) Leptin resistance exacerbates diet-induced obesity and is associated with diminished maximal leptin signalling capacity in rats. Diabetologia 48:1075-1083

40. Zhang J, Matheny MK, Tumer N, Mitchell MK, Scarpace PJ (2007) Leptin antagonist reveals that the normalization of caloric intake and the thermic effect of food following high-fat feeding are leptin dependent. Am J Physiol Regul Integr Comp Physiol 292:R868-R874

41. Horvath TL (2005) The hardship of obesity: a soft-wired hypothalamus. Nat Neurosci 8:561-565

42. Horvath TL, Naftolin F, Kalra SP, Leranth C (1992) Neuropeptide-Y innervation of beta-endorphin-containing cells in the rat mediobasal hypothalamus: a light and electron microscopic double immunostaining analysis. Endocrinology 131:24612467

43. Cowley MA, Smart JL, Rubinstein M et al (2001) Leptin activates anorexigenic POMC neurons through a neural network in the arcuate nucleus. Nature 411:480-484 